\title{
Intramolecular $\mathrm{NH} / \pi$ complexes of 2-allylaniline derivatives in the ground and excited states
}

Edgar A. Leo, Rosa Tormos, Sandra Monti, Luis R. Domingo, and Miguel A. Miranda*

\section{Contents of Supporting information:}

S1: This page.

S2: ${ }^{1} \mathrm{H}$ NMR spectrum of compound $\mathbf{1 b}$.

S3: ${ }^{13} \mathrm{C}$ NMR spectrum of compound $\mathbf{1 b}$.

S4: ${ }^{1} \mathrm{H}$ NMR spectrum of compound $\mathbf{2 b}$.

S5: ${ }^{13} \mathrm{C}$ NMR spectrum of compound $\mathbf{2 b}$.

S6: ${ }^{1}$ H NMR spectrum of compound cis-3b.

S7: ${ }^{13} \mathrm{C}$ NMR spectrum of compound cis-3b.

S8: ${ }^{1} \mathrm{H}$ NMR spectrum of compound trans-3b.

S9: ${ }^{13} \mathrm{C}$ NMR spectrum of compound trans-3b.

S10: Relevant NOE interactions in cis $\mathbf{- 3 b}$ and trans $\mathbf{- 3 b}$. 

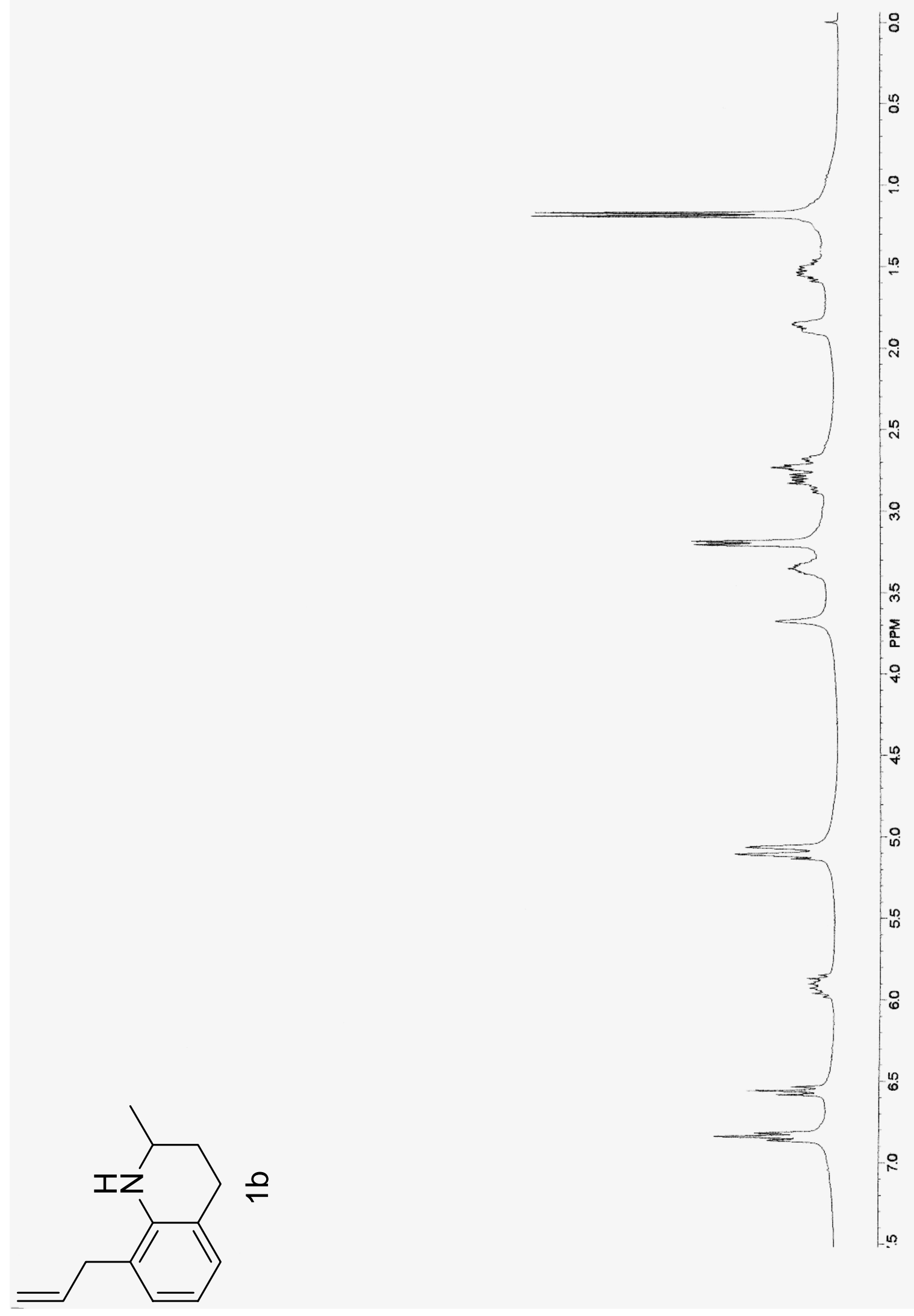


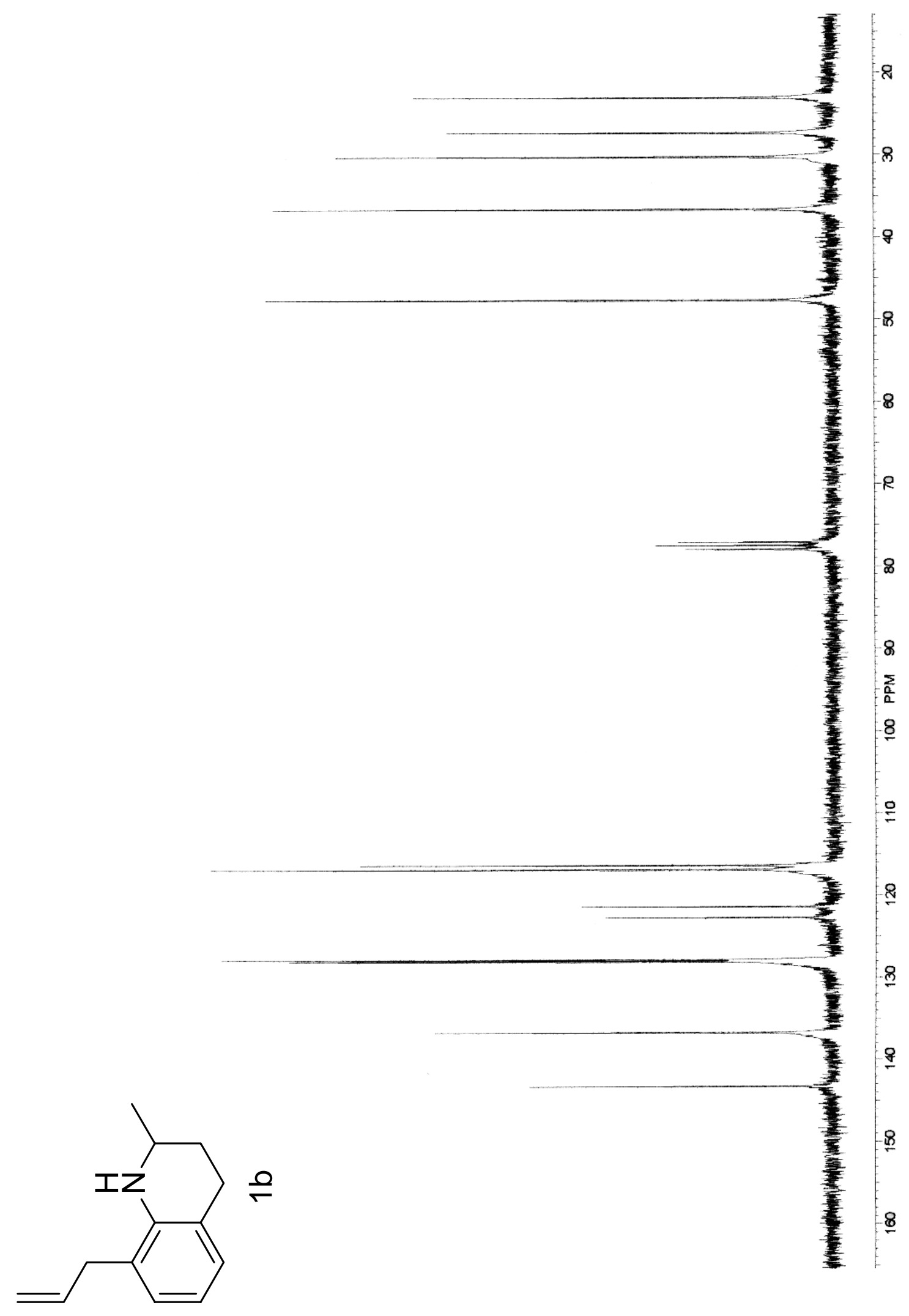




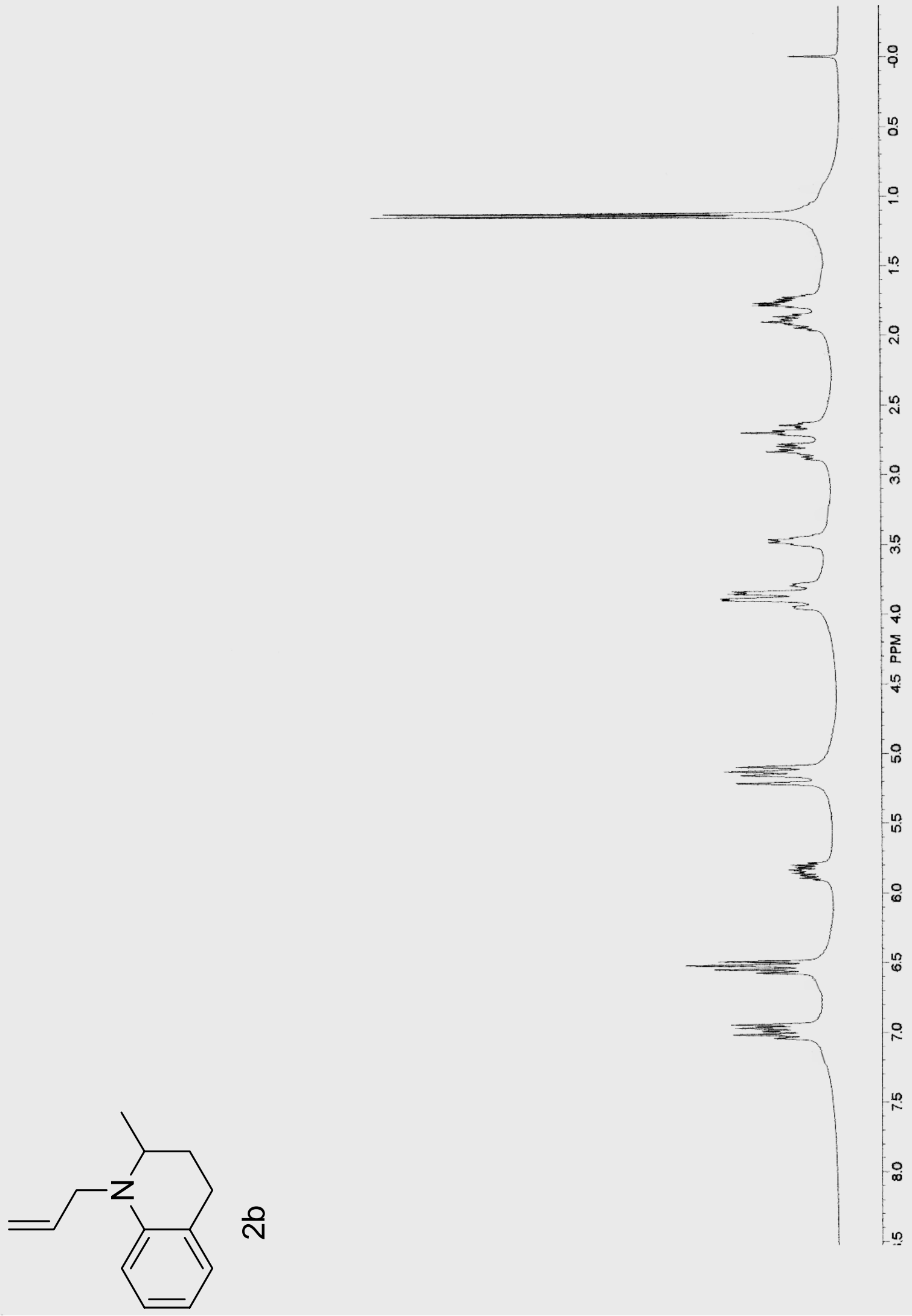




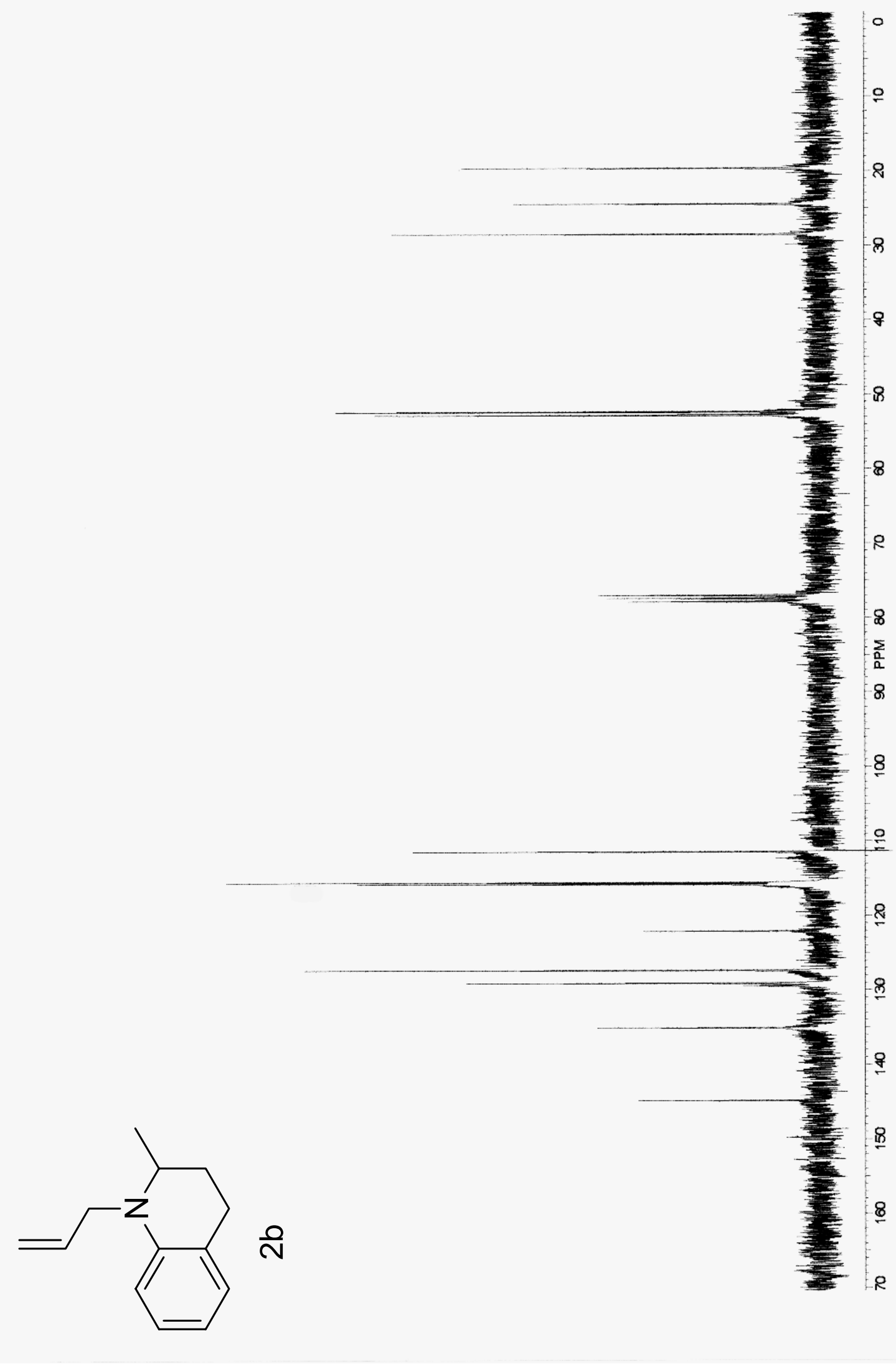




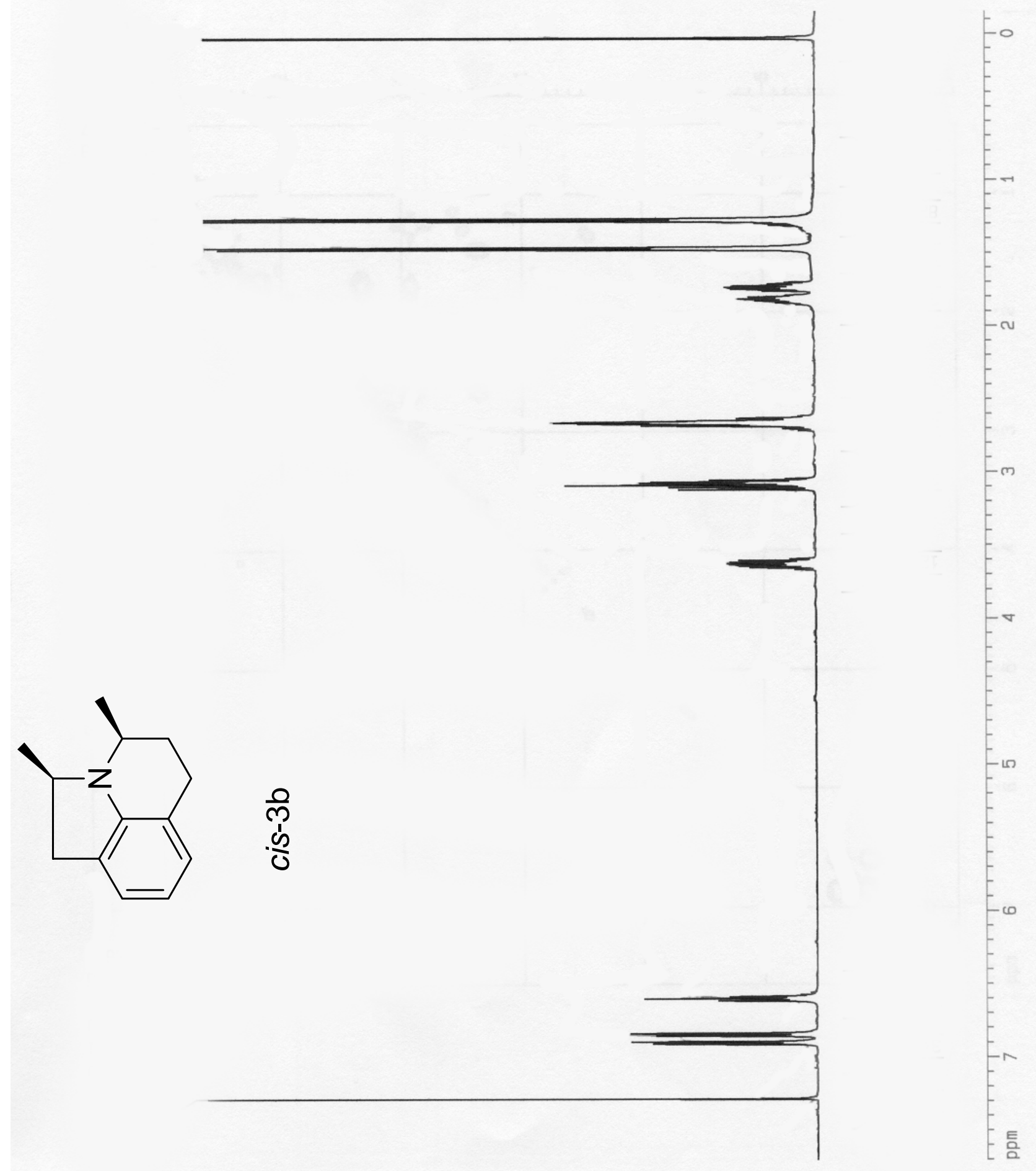


in

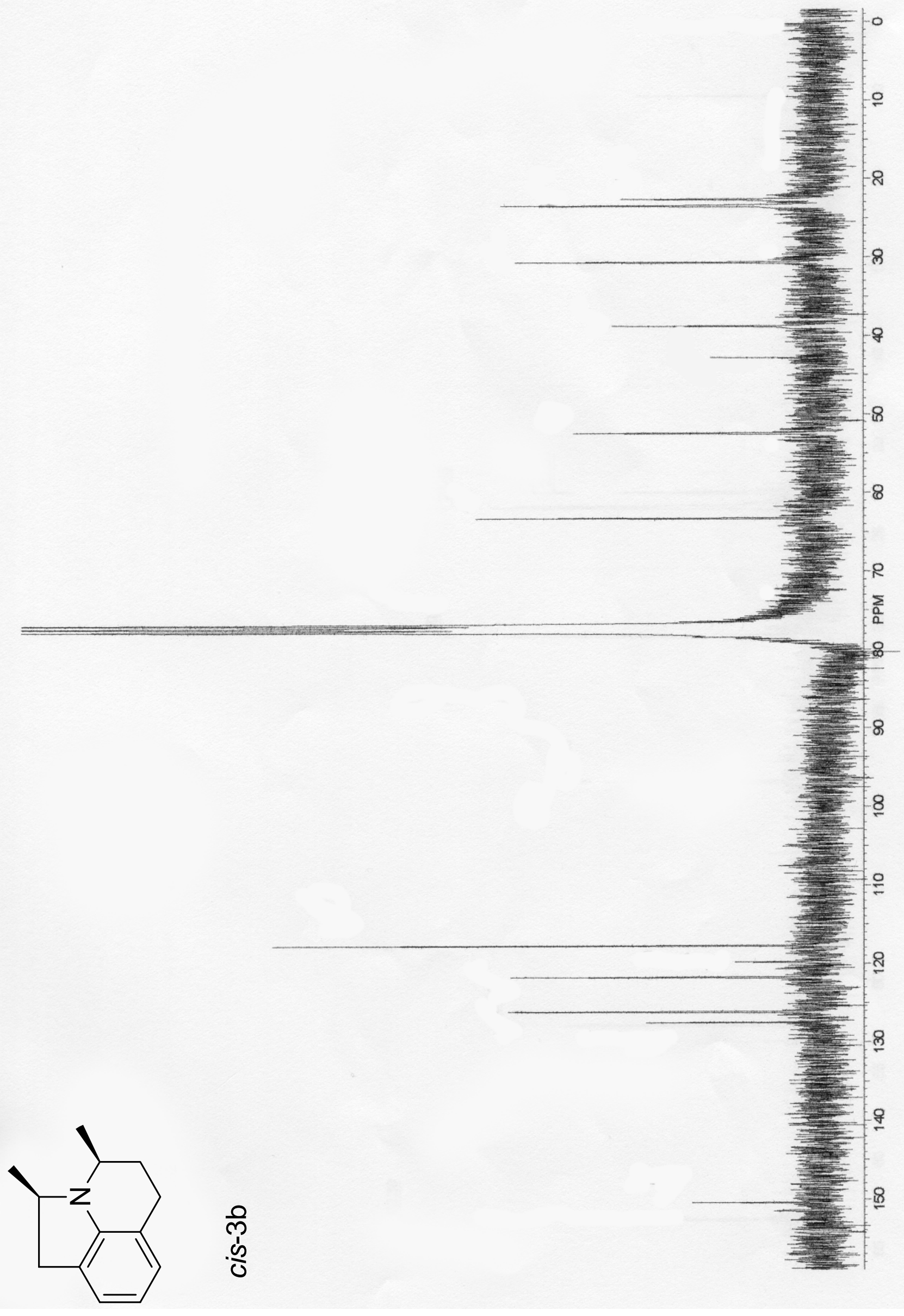




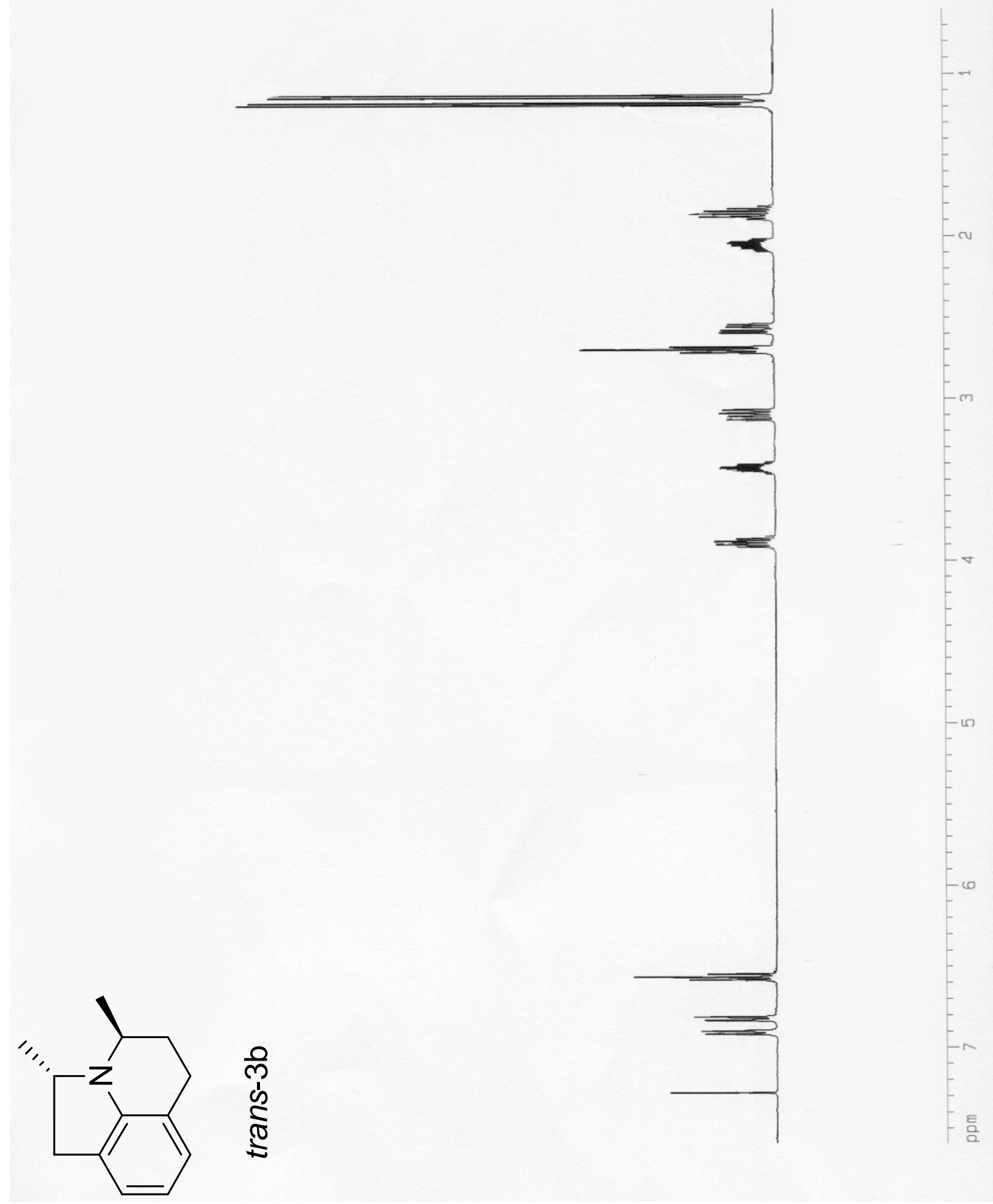




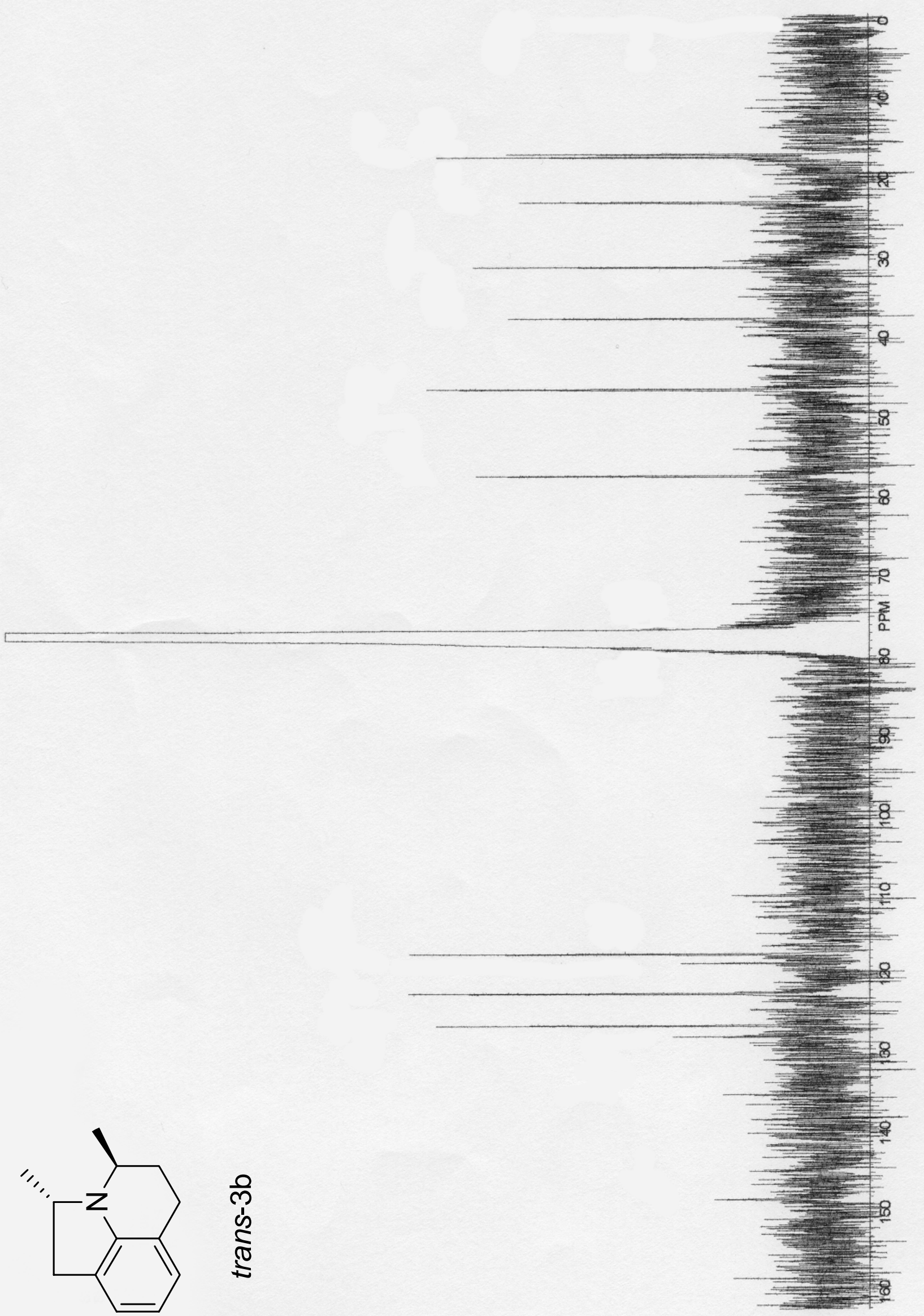



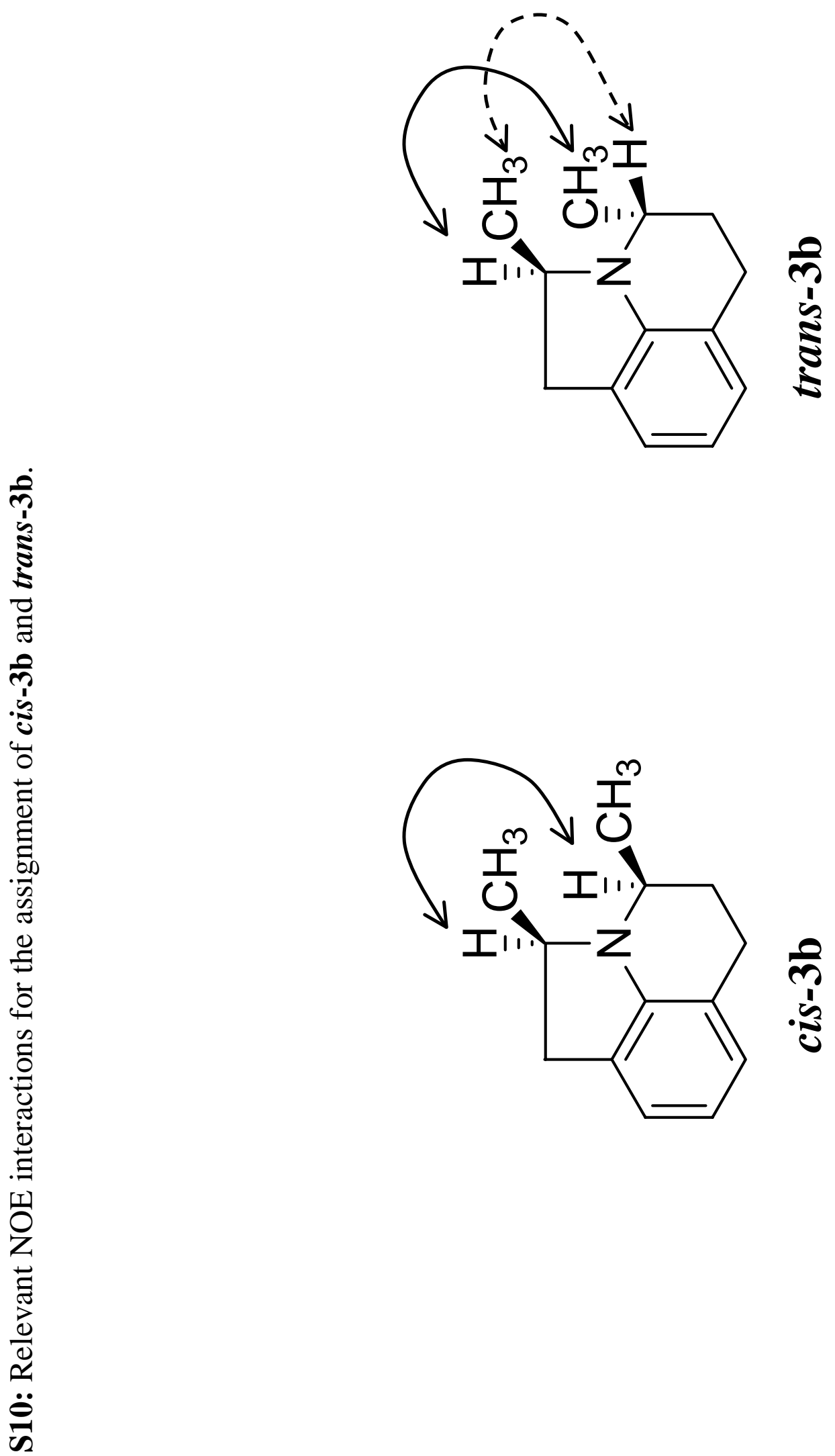